\title{
A state of the art on railway simulation modelling software and its application to designing baggage transfer service
}

\author{
Ho Ki Yeung ${ }^{a *}$, Marin Marinov ${ }^{b}$ \\ ${ }^{a}$ Newcastle University, School of Mechanical and System Engineering, Newcastle-Upon-Tyne, NE1 7RU, United \\ Kingdom \\ ${ }^{\mathrm{b}}$ Newcastle University, Newrail, Newcastle-Upon-Tyne, NE1 7RU, United Kingdom \\ * Ho Ki Yeung. Tel.: [(+44)07572226411], E-mail address: [h.k.yeung@newcastle.ac.uk]
}

\begin{abstract}
There is a new baggage transfer service suggested in Newcastle Central Station, in order to prove that the service is feasible, it is needed to test the idea by creating a simulation model about the system before fully implementation in reality. The main aim of this project is to review literatures on numerous simulation modelling software and give suggestions on which one should be best used in supporting the design of such system. This paper has compared 5 different common simulation software used by railway industry by looking at their forms and natures as well as their applications from a number of literatures. It is suggested that SIMUL8, a macroscopic discrete event based software, should be the best simulation software to be used among the 5 compared ones because of its simplicity and the ability to give analysis results just detailed enough for investigation of such baggage transfer system. Some other background research related to railway policies, passenger figures and studies about baggage transfer system has also been conducted throughout this paper in the aid of facilitating the design of this baggage transfer system using the software. There are also some possible suggestions to improve the reliability of the simulation results made at the end of the paper.
\end{abstract}

\section{Introduction}

Due to the absence of current baggage transfer service in any of the UK's train station, it is proposed to launch a new baggage transfer system at Newcastle Central Station, one of the national railway hubs, to serve different destinations across the country to facilitate boarding and alighting of trains for those carrying large luggage to give a smoother and thus more comfortable journey. Although the proposal only related to Newcastle Central station, it can be extended to any part of the country in the future if proven feasible. However, in order to prove that the idea is feasible in reality, there should be extensive research on this topic and then validate the system with the aid of simulation modelling.

Due to the high number of availability of simulation software in the market, the aim of this project is to review literatures on railway simulation modelling software and give suggestions on which ones can be used in supporting the design of the proposed baggage transfer system. 


\subsection{Motivation}

In UK, there is an extensive network of railway covering most part of the country which provides a generally shorter journey time than other means of road transport. In order to attract more travellers giving up their cars and use railway for intercity travel, it is essential to provide them with a smooth and comfortable journey. Dealing with heavy luggage plays an important role in improving the journey. However, it was found that one quarter of UK railway customers showed dissatisfied view towards the space for luggage on train (Transport Focus, 2016). As a result, a baggage transfer system which allows travellers dropping off their baggage just before their actual travelling time so as to achieve baggageless journey is designed.

However, due to the high costs and risks in implementing such a service in reality, careful planning is by all means essential. Running simulation model can give an idea about how the system would perform like and it can also better utilize the system to cut down operation cost. Nevertheless, there is a lot of simulation software available for example Arena, SIMUL8, OpenTrack and a lot more. And there is relatively little work done on comparing different types of programme about which ones can be suitably used in each case. Some of the programmes are more specific to railway industry and some are more general. Some give a great detailed analysis which may not be necessary for all situations. These confuse users about which type of software should they use. As a result, this paper is intended to give an idea about what is available and how to choose a suitable one for a system, in this case a baggage transfer system.

\section{Background Information}

In order to better understand the situations of launching the baggage transfer service in Newcastle Central Station, some background researches are essential. The area of study include railway policies on on-board baggage, passenger figures showing the purpose of travel, some basic information about Newcastle Central Station and also some case studies about similar baggage services available whether or not in the UK.

\subsection{Railway Policy}

According to National Rail Conditions of Carriage, each passenger can take one piece of hand luggage which can be held on lap if required plus 2 extra items with size not more than $30 \mathrm{~cm} \times 70 \mathrm{~cm}$ $x 90 \mathrm{~cm}$. Each passenger should be able to manage their luggage without any extra help from rail staff member. However, some items that cannot be brought on board including stuff that may cause injury, inconvenience or a nuisance; there is not enough room for it; loading or unloading would cause delay of train or it is not packed in a suitable manner. Any item that exceeds the limit may be required to be conveyed into a separate carriage with subjection to an extra charge but not exceeding half of the adult single fare for the journey (National Rail, 2015).

\subsection{Passenger Figures}

In year 2015, 20\% of passenger journeys are using National Rail and there is a growth in trend in rail usage in the last 20 years across the UK (Department for Transport, 2017). 8\% of English people used National Rail at least once a week with the age group that used rail the most being 21-29 years old for both sexes (Department for Transport, 2017).

For the purpose of long distance train journeys, the majority is to visit friends or relatives (54\%) followed by days out and holiday (28\%) and then business trip (19\%). For the reason to use train instead of car, a majority suggested that it was easier and quicker by train (40\%) followed by not willing to drive (20\%) (Department for Transport, 2015). 
It is also found that the use of railway increases with income. People with the highest income households travel almost 6 times more than the lowest income households by rail in 2015. Similarly, managerial and professional people travel by rail far more than those who are unemployed or doing routine and manual jobs because of commuting and business trip that it was 3 times more than the lowest income group. Followed by business trip, the next purpose of travel is visiting friends which share similar proportion as the other income groups (Department for Transport, 2016).

\subsection{Technical Characteristic of Newcastle Central Station}

Newcastle Central Station is one of the largest stations in north east England. This station lines on East Coast Main Line (ECML) connecting London and North East Scotland including Edinburgh and Aberdeen. Virgin Trains East Coast is currently managing the station and providing services running along ECML. Apart from this, Arriva Cross Country provides services that connect Scotland and South or South West England via Birmingham. First TransPennine Express also provides services connecting Newcastle to Manchester and Liverpool. Northern provides services connecting Newcastle to the North West of England. It can therefore be seen that Newcastle Central Station is a hub for services to various destinations across the whole country.

Newcastle Central Station is the busiest station in the region with hundreds of services each day. There are over 8.1millions usage in year 2015-2016 with an increase of around $2 \%$ from the previous year (Office of Rail and Road, 2016). There will be extra seats provided by the new trains on Virgin Trains East Coast in 2018 as well as up to 22 minutes reduced for journey time (bbc, 2017). Also, Office of Rail and Road has approved that there will be an introduction of new train operator by First Group running on ECML between London and Edinburgh calling at Newcastle from 2021 (Larkinson, 2016). With all these favourable factors, there should be a continuous growth of passenger number of the station in the future.

\subsection{Similar Services}

There is no luggage transfer service provided by any rail operators in the UK currently. Virgin Trains used to have a luggage delivery service called Virgin Bag Magic. This service allows a courier company, Parcels 4 Delivery (P4D), to pick up the baggage on the day before the actual travel date from any address including home, office or hotel. The baggage would be delivered using courier vans on the following day or a pre-selected date to any address in the UK (MAGRATH, 2014). The baggage allowed to be delivered includes bags, cases, presents or bicycles but the service has come to an end on in 2016 without mentioning any reason from Virgin Trains or P4D (Virgin Trains, n.d.)and (p4d, n.d.).

The only method to get the baggage shipped currently is by using courier service using road transport like HGVs or vans. Some of the services provide drop off in shop for example Parcelforce and DPD. Service like InPost yet allows users to drop off and pick up their baggage at destined selfmanaging lockers with however very limited size. Some of the other couriers provide door-to-door courier service for example CitySprint, DHL and UPS. However, all these services are intended for shipment of parcels and express services internationally and thus charging the user a premium fare.

There is however some similar baggage transfer services outside UK. For example Hong Kong Airport Express Line allows free in-town check-in service for major airlines provided in Hong Kong Station and Kowloon Station to allow passengers to travel the train with baggage free. For intercity trains, Hong Kong-China Through trains, Swiss SBB trains and Austria ÖBB trains all provide luggage transfer service for both domestic and international cases. 


\section{Review of Baggage System Design}

\subsection{Material Handling System}

A material handling system can improve the overall efficiency and reliability of the system which is important for different modern industries including transportation. The system can give extra value to a running business by improving the flexibility and productivity which thus lowering the cost of operation when designed and controlled well (Rockwell Automation, 2017). According to Johnstone (Johnstone, et al., 2015), material handling system can boost the productivity by precision delivery of product. This is applicable to an airport baggage handling system and can reduce the time for delivery and lower the chance of delays also provide better throughput.

For large systems for example airport baggage handling system, parcel or mail centres, they are using different forms of conveyors in different locations where the products merge from different sources (Gunal, et al., 1996). Conveyor systems carry bags using belts, chutes or rollers. They can be used as an independent system or integrated with some other sorting systems and it is easily installed and adjustable (Vickers \& Chinn, 1998).

\subsection{Baggage Handling System}

Baggage handling system is important in airports to deal with large amount of baggage from different flights each day including routing, scheduling, cart management and security control. Each part of the control should be linked together as a smooth chain to avoid delays. This has been studied in a few research papers namely (Zeinaly, et al., 2015) (Neufville, 1994). For the luggage transfer service that is currently designing for railway industry, it is very similar to airport baggage handling system but only with a much smaller scale.

Other than conveyor-based system as mentioned in Section 3.1, the handling system can also be automated by using destination coded vehicles (DCVs) for more efficient work (Tarau, et al., 2010). DCV systems use individual vehicles that connect every input and output to form a railway network which travels faster than conveyors (Tarau, et al., 2008). The capacity of the system is usually determined by the number of DCVs as they are limited while empty carts are in surplus causing line unbalancing problem (Neufville, 1994).

\subsection{Baggage Security}

Only $34 \%$ of the respondents from a survey result published by Patil et al. (Patil, et al., 2013) show concern about terrorism to their security during metro or train travel. And there is a trade-off between security and time, costs and privacy of the passengers which stirs up a debate. However, the more the money spend on security, the less the vulnerability of the transport system with lower chance of disastrous attacks (Salter, 2008). There have been random baggage checks in public transport hubs in the US for security issues and only 6 people out of over 20,000s in 2 weeks' time refused to participate and were not allowed to enter the system (Luczak, 2005). As a result, the importance of security on the check-in bags should not be neglected and baggage check should be understood and accepted by general public.

\section{An overview of Simulation Software}

Simulation modelling is one of the most effective ways of testing a new proposed design. A simulation is an operation of a system's imitation that it should be equivalent to the actual real world system as similar as possible (Abril, et al., 2008). Nash and Huerlimann (Nash \& Huerlimann, 
2004)have listed 3 main reasons why computer simulation is very helpful for evaluating new railway improvement strategies:

1. Understanding of rail line capacity

2. Understanding the overall impact on the alternation of the intensively interrelated infrastructure in the network

3. Reduce long term operating cost due to poor planning on infrastructure

Many transportational studies have been using different kinds of modelling methods including mathematical modelling like (Marinov \& Reece, 2015) as well as simulation modelling to analyse the prototype idea. Simulation modelling provides a wide range of situations and the parameters are easily modified, it can be applied to many transportation aspects including Metro signalling for driverless operation (Powell, et al., 2016), freight train operation in yard (Marinov \& Viegas, 2009) (Marinov \& Viegas, 2011), And some similar modelling topic related to this project about baggage transfer on rail has been done by previous studies (Brice, et al., 2015).

There are different types of simulation method but most common ones are discrete event simulation and continuous simulation. The definitions of both simulation types by Nance (Nance, 1993) are:

- Discrete event simulation is defined as "a mathematical/ logical model of a physical system that portrays state changes at precision points in simulated time."

- Continuous simulation is defined as "equation models, often of physical systems, which do not portray precise time and state relationship that result in discontinuity."

Discrete event simulation studies the change of system with changes at different points in time and is best for situations where there are variables changes in discrete time and step while continuous simulation is used when the variables change continuously and is usually based on mathematical functions (Özgün \& Barlas, 2009).

From a few journals studied, the basic procedures in generating a simulation model can be summarised as follow (Sedláček, 2014) (Pouryousef, et al., 2015):

1. Determination of the objectives of the model to be simulated- Formulation of problem by understanding the needs of the proposed system and create a conceptual model based on the criteria.

2. Collection of information that is required for producing the simulation model- Collect the data that is essential to increase the exactness of the simulation model with regard to the overall objectives.

3. Construction of simulation model- Build the simulation model with respect to the prepared data from step 2.

4. Revision of the built model- Verification of the model constructed with the conceptual model initially that matches with the ideas in step 1.

5. Implementation and experimental parameters on the simulation model- Make adjustments of the bottlenecks of the system and then optimize the model to determine the best possible solution of the system.

6. Incorporation of the simulation results into the system in reality- The results to be implemented into real system. 


\subsection{Software Available}

There is different simulation software available in the market which is suitable in simulating a system operation. Such as OpenTrack, SIMUL8, XpressMP, Arena, Railsys. Some of them are more general and are suitable for modelling of different cases in any of the industry in a more general way while some are more specific to railway sectors. For the specific commercial railway simulation software, according to Pouryousef et al. (Pouryousef, et al., 2015), the software is generally around looking at two major components: 1) Movement of train and 2) Dispatch of train. The first one uses the system component data for example station, yard and track layout, signalling system and also the specification of rolling stocks as input to determine the train speed and scheduling. For the latter one, the program is using the timetable of the system to investigate different elements like delays, transit time and fuel consumption.

Some of the more common simulation software suitable for railway modelling would be discussed below:

\subsubsection{Xpress MP}

Xpress MP is a general one which uses algorithms to study the mathematical modelling. Different scenario can be formed by altering the constraints and variables of the functions for example the cost per unit volume of goods to be transported or the emission data. Lawley et al. (Lawley, et al., 2008) used this program with $\mathrm{C}++$ language to generate a model for improving regular rail freight transports scheduling in minimizing the delays and increasing the overall capacity. Similarly, Kuby et al. (Kuby, et al., 2001)used this program from a mathematical model to evaluate the capacity of the rail network and plan for the medium term (15 years) of investment strategies for the development of railway system In China which was already overburdened.

\subsubsection{OpenTrack}

OpenTrack is another program that is more specific to railway transport modelling. It runs as a hybrid of discrete-continuous simulation and object-oriented programme (Cha \& Mun, 2014). The software simulates the movement of trains in the system based on timetable. It can be used in most of the rail industry including but not limited to metro and light rails, intercity trains and freight trains.

According to the software provider (OpenTrack, 2017), the software can perform the following tasks:

- Determining the capacity of the lines and stations

- Headways and running time calculations

- Evaluation of different signal systems

- Energy consumptions

- Construction of timetable

There are a few journal papers reviewed which chose OpenTrack as the software to run the simulation modelling. The topics include metro signalling for driverless operation (Powell, et al., 2016), tilting trains to be used in metro (Darlton \& Marinov, 2015), high speed railway in China (Chen \& Han, 2014) and proposal of increase in capacity of the railway line in Croatia (Ljubaj, et al., 2017).

\subsubsection{Railsys}

RailSys is on operation management software system which integrates timetable construction and infrastructure management with microscopic simulation. It is one of the most common timetable 
based simulation software in Europe (Pouryousef, et al., 2015). The programme using synchronous simulation requires an initial timetable for the simulation and it would then compress to improve the original timetable to utilize more efficient capacity of the system (Pouryousef \& Lautala, 2015). It is useful in planning infrastructure, building timetable and logistic planning of large project (Grube, et al., 2011).

There are quite a few on paper reviewed using RailSys as the programme to solve different railway problems. Sipila (Sipila, 2014)used the software to create timetables for single track line running with high speed train based on delay analysis. Gille and Siefer (Gille \& Siefer, 2013)used it to determine the service quality and improve the capacity of the rail line capacity.

\subsubsection{Arena}

Arena is a discrete event-based software which it is a simulation environment that include input data analysis, model building, interactive execution with tracing, real-time graphical animation based on SIMAN/ Cinema, verification of results and output analysis. The system is not restricted to any specific industry and there are some templates available to use as a start-up when creating the model where they may be useful in areas like health care understanding, investigating on traffic flow and so on (Collins \& Watson, 1993) (Lee, et al., 1996).

Arena is widely used in different areas but for railway transportation, it has been used in modelling of logistical rail-guided vehicles (Lee, et al., 1996), designing a railway yard to accommodate high speed rail and conventional rail in the future (Abbott \& Marinov, 2015), analysis of urban freight using metro (Motragh \& Marinov, 2012) and so on.

\subsubsection{SIMUL8}

SIMUL 8 is a discrete event simulation which analyse the behaviour of the system by testing with computational model and therefore it is best for planning, designing and optimizing the real process. The block building exercise makes it an easy platform to create a model as everything is visualized which can then be easily traced to view the structure of the system and understand the links and operation (Sedláček, 2014). It is different from much other software as its model building approach is based on the ability to draw scenario cases and filling in components data when required (Vayenas, et al., 2005). SIMUL8 allows both single and multiple simulation runs. The trial results would indicate how well the system performed by showing graphically and statistically (Shalliker \& Rickets, 2006).

There are very broad uses of SIMUL8 software for instance, logistics and transport sectors. Vidalakis et al. (Vidalakis, et al., 1994) used the software to model a logistic supply chain with merchant's perspectives because of its simplicity in building the logic. Brice et al. (Brice, et al., 2015) used it to model freight train operation in urban rail. Wales and Marinov (Wales \& Marinov, 2015) used the programme to analyse the system's performance for delay mitigation.

\subsection{Classifications}

There are generally three types of simulation forms as described by Casalicchio et al. (Casalicchio, et al., 2010).

Microscopic simulation uses a bottom up approach which considers different behaviour of each individual entity and takes in with one or more parameters. As a result the processing is very demanding on computer and time consuming. It is usually run as a small scope for highly detailed analysis. 
Macroscopic simulation reduces drastically the costs and efforts as it focuses on large area as the upper level of the system. This means groups of similar entities are formed and share the same properties. This method reduces the precision of the simulation but gives good overall view of the system.

Hybrid form is a mixture of microscopic and macroscopic simulation where some of the entities are treated individually while some other types are treated as an identical in macroscopic form. It is therefore similar to continuous flux but with a greater details level for some of the important entities.

Microscopic simulation software like RailSys and OpenTrack is suitable for highly detailed applications for example precise geometry of track (Douglas, et al., 2016). Macroscopic simulation is however suitable for less detailed cases for example traffic planning and strategic infrastructure planning (Gille, et al., 2008).

\subsection{Limitations}

Hall (Hall, 1991)suggested that simulation is a strong tool to evaluate the model behaviour. However, the simulation result can only predict the system behaviour on average and the exact values and numbers in reality cannot be shown or can only be predicted by speculation. There are some other literatures stating that there are some limitations about using simulations. For example, Vu et al. (Le, et al., 2012)suggested that it is usually assumed that the baggage size is constant that being put into the system ideally. However, there are different types and number of baggage being checked in including boxes as well in reality. This affects the occupancy of the system as it varies with size and nature and eventually affects the overall capacity of the baggage handling system.

\section{Evaluations}

Table 1 below summarised the 5 simulation modelling software reviewed from Section 4 and their nature, purpose and forms are compared against each other.

Table 1: Summary of software reviewed

\begin{tabular}{|l|l|l|l|}
\hline Software & Purpose & Form & Nature \\
\hline Arena & General & Macro & Discrete event \\
\hline SIMUL8 & General & Macro & Discrete event \\
\hline XpressMP & General & Micro/Macro & Continuous \\
\hline RailSys & Railway & Micro & Discrete event \\
\hline OpenTrack & Railway & Micro/Macro & Discrete event \\
\hline
\end{tabular}

From the result from Table 1, RailSys and OpenTrack are both specific for railway designs and they are both can be used as microscopic simulation. For the other 3 programmes, they can be more general used with no specific area of industry. And these programmes are modelling in a macroscopic way which means the work items are at higher level and more general in any circumstances.

As seen from the Table 1 above, most of the software reviewed are discrete event based simulation programme except XpressMP which uses mathematical equations to form continuous simulation. One of the most significant benefits of discrete event simulation is that they are relatively simple for any users to create their own models and allowing variables events to be in the desirable time interval. However, continuous simulation programmes often involves specific kind of writing languages to be complied with the programme which means that they are relatively less userfriendly. 


\subsection{Choice of option}

As the aim of making a simulation model is to give a general view to show how well the system can cope with the baggage in the station. Therefore, the basic requirement to choose the suitable simulation modelling programme for the baggage transfer system include the ease of generating a model, allow to simulate with addition of events at desired time and gives a general idea to prove the service is feasible.

In order to keep the simulation simple, discrete event based software should be chosen and they allow the system to have added variable changes at different points. This means XpressMP is relatively not suitable in this case.

In the simulation, each individual baggage does not have to be modelled on its own. As such, a higher level of work item is needed to give a general view of the system. However, RailSys and OpenTrack only provides a microscopic view for the railway system operation which emphasis too much on the individual movement of trains, infrastructures and timetabling and is too precise and therefore they are not suitable for investigation of baggage handling system.

As such, only Arena and SIMUL8 are the two left for option. Both of the software are suitable for creating a model for the baggage transfer system but Arena is more famous on generating graphics and animations while SIMUL8 is good for giving graphs and data which is compile with MS Excel for further interpretation. SIMUL8 uses few modelling objects which is enough to define the problem situation to make things less complicated. As Brice et al. (Brice, et al., 2015) suggested, SIMUL8 software is a good option to be used in a baggage transfer system in his paper. It is because the software is simple to use as well as giving broader range for less complex modelling. Therefore SIMUL8 should be the best simulation programme to be used for modelling the baggage transfer system.

\subsection{SIMUL 8 fundamentals}

SIMUL8 operates with Building Blocks which include (Marinov \& Viegas, 2011):

1. Work Entry Point- Arrival of work items to the system and the arrival pattern can be deterministic or stochastic behaviour.

2. Queue- The point where the work items are waiting for the next process.

3. Work Centres- System servers or machines where process is taking place here and the output of this stage will be passed to other point of system for further working, storage or direct delivery through work exit point.

4. Storage Point- As a buffer or a queue to gather (semi-)finished work items for moving up to the next process

5. Work Exit Point- The point where the work items leave the system and where the service or process is meant to be completed. There can be over one Work Exit Point for example one exit point to the delivery of items while some defective items are sent for scrap and disposed.

6. Work Items- The object that are brought to the work entry point for further process along the simulation modelling system.

7. Resources- Any machines, employee, operator, signal etc. that required fulfilling the tasks and processes at different work centres. 
In the case of baggage transfer service, the work item is defined as the baggage to be or have been transferred. The resources would be anything that is in the system including check in desk, staff member, $x$-ray machine for security, karts for movements of baggage around station and storage racks etc which some of them have been discussed in Section 3. Entry point would be the check in desk at station where customers would drop off their bags or the arrival of bags from other destinations prior to customer pick up. Queue can be where the luggage is waiting to be checked in on arrival. Storage point would be the racks behind the check in point where the luggage is waiting to be shipped or picked up by customers. Work exit point would be the point where the baggage leaves the check in centre for shipment or picked up.

\subsection{Discussions}

From the background research in Section 2, despite rail transport is not the most popular mobility mode for intercity travel, it can be noted that there is a growth in passenger numbers for years in the UK. There are many ways to attract more people using this more sustainable and environmentally friendly mode of transport. One of the possible ways is being better baggage handling to smooth the passengers' journeys. There is currently no such service available in the UK and therefore there is potential market for creating one. In order to support the idea to create a baggage transfer system in railway station, simulation modelling is helpful in testing out the system without actual adaptation on it.

With the definition of the essential building blocks in Section 5.2, one can start creating the model using SIMUL 8 software for any of the station but not only limited to Newcastle Central Station by putting in the suitable data for example, prediction of the number of customers based on the usage of the station, prediction of baggage arrival time based on the actual timetable to improve the reliability of the model.

Different scenarios can also be created easily for example using a separate freight train for transporting the baggage or only transporting using existing passenger services. By comparing the simulation results of each case, the best possible solutions for such baggage transfer service can be obtained and this provides good evidence to prove to the decision maker that the idea can be implemented in reality to help improving rail transport as a whole.

However, it is noted that one cannot only depend on simulation result to conclude that the newly proposed system is successful. There are a lot of controls related to policies, costs and security issues. Moreover, it has been discussed in Section 4.3 that there are some limitations about such modelling system. However, the reliability of the simulation results can be improved by conducting and including some market research into the model including:

- Estimation of number of baggage by investigating the interest of public

- Estimation of size of baggage which related to storage and carrying capacity of the system by observation

- Estimation of flow of passengers by timetable studying and observations in different days throughout the week to improve crowd control

These factors should be added to the simulation model ultimately if the first stage of simulation is proven the idea is feasible. 


\section{Conclusions}

In order to agree that the proposed baggage transfer service is feasible, it is required to create a simulation about the service before fully implementation in reality. This paper has conducted some background research related to relevant railway policies, passenger and station figures and information as well as other similar services around the world. There is also a review on baggage transfer system completed which can give a general idea of how the system can be modelled in simulation software. Followed by this is an overview of what simulation software is available with detailed analysis of how they can be used.

It is suggested that SIMUL8, a macroscopic discrete event based software, should be the best simulation software among the 5 computer programmes studied because of its simplicity with the ability to give analysis just detailed enough for the investigation of such baggage transfer system. There are however some limitations about simulation modelling which should be noted as a deviation from the real system. As a result, there are some improvement suggestions given which include market research about passengers' interest and practice.

\section{References}

Abbott, D. \& Marinov, M. V., 2015. An event based simulation model to evaluate the design of a rail interchange yard, which provides service to high speed and conventional railways. Simulation Modelling Practice and Theory, Volume 52, pp. 15-39.

Abril, M. et al., 2008. An Assessment of railway capacity. Transportation Research Part E, 44(5), pp. 774-806.

bbc, 2017. Work begins on Virgin Trains' East Coast Main Line fleet. [Online] Available at: http://www.bbc.co.uk/news/uk-england-39808537 [Accessed 15 May 2017].

Brice, D., Marinov, M. \& Rüger, B., 2015. A Newly Designed Baggage Transfer System Implemented Using Event-Based Simulations. Urban Rail Transit, 1(4), pp. 194-214.

Casalicchio, E., Galli, E. \& Tucci, S., 2010. Macro and Micro Agent-based Modeling and Simulation of Critical Infrastructures. Roma, IEEE, pp. 79-81.

Cha, M. H. \& Mun, D., 2014. Discrete event simulation of Maglev transport considering traffic waves. Journal of Computational Design and Engineering, 1(4), pp. 233-242.

Chen, Z. \& Han, B. M., 2014. Simulation Study Based on OpenTrack on Carrying Capacity in District of Beijing-Shanghai High-Speed Railway. Applied Mechanics and Materials, Volume 505-506, pp. 567570.

Collins, N. \& Watson, C. M., 1993. INTRODUCTION TO ARENA. Los Angeles, s.n.

Darlton, A. O. \& Marinov, M., 2015. Suitability of Tilting Technology to the Tyne and Wear Metro System. Urban Rail Transit, 1(1), pp. 47-68.

Department for Transport, 2015. Public attitudes towards train services: results from the February 2015 Opinions and Lifestyle Survey, s.I.: Department for Transport.

Department for Transport, 2016. National Travel Survey, s.l.: Department for Transport.

Department for Transport, 2017. Rail Passenger Factsheet, s.l.: Department for Transport. 
Department for Transport, 2017. Rail Trends Factsheet, s.l.: Department for Transport.

Douglas, H. et al., 2016. Method for validating the train motion equations used for passenger rail vehicle simulation. Journal of Rail and Rapid Transit, 231(4), pp. 455-469.

Gille, A., Klemenz, M. \& Siefer, T., 2008. Applying multiscaling analysis to detect capacity resources in railway networks. Computers in Railways, Volume XI, pp. 595-604.

Gille, A. \& Siefer, T., 2013. Sophisticated capacity determination using simulation. Washington DC, s.n.

Grube, P., Núñez, F. \& Cipriano, A., 2011. An event-driven simulator for multi-line metro systems and its application to Santiago de Chile metropolitan rail network. Simulation Modelling Practice and Theory, Volume 19, pp. 393-405.

Gunal, A., Sadakane, S. \& Williams, E., 1996. Modeling of chain conveyors and their equipment interfaces. s.l., s.n.

Hall, R. W., 1991. Queuing Methods For Services And Manufacturing. s.I.:Prentice Hall.

Johnstone, M., Creighton, D. \& Nahavandi, S., 2015. Simulation-based baggage handling system merge analysis. Simulation Modelling Practice and Theory, Volume 53, pp. 45-49.

Kuby, M., Xu, Z. \& Xie, X., 2001. Railway network design with multiple project stages and time sequencing. Journal of Geographical Systems, Issue 3, pp. 25-47.

Larkinson, J., 2016. East Coast Main Line decision letter, s.l.: Office of Rail and Road.

Lawley, M. et al., 2008. A time-space scheduling model for optimizing recurring bulk railcar deliveries. Transportation Research Part B, Volume 42, pp. 438-454.

Lee, S., Souza, R. d. \& Ong, E., 1996. Simulatio:n modelling of a narrow aisle automated storage and retrieval. system (AS/RS) serviced by rail-guided vehicles. Computers in Industry, Volume 30, pp. 241253.

Le, V. T. et al., 2012. A Generalised Data Analysis Approach for Baggage Handling Systems Simulation. Seoul, s.n.

Ljubaj, I., Mlinarić, T. J. \& Radonjić, D., 2017. Proposed solutions for increasing the capacity of the Mediterranean Corridor on section Zagreb - Rijeka. Procedia Engineering, Volume 192, pp. 545-550.

Luczak, M., 2005. Transit Security What more can be done. Railway Age, pp. 37-43.

MAGRATH, A., 2014. Virgin Trains launches new luggage delivery service allowing passengers to post presents home in time for Christmas ... wrapped up by elves. [Online]

Available at: www.dailymail.co.uk/travel/travel news/article-2842377/Virgin-Trains-launches-new-

Bag-Magic-luggage-delivery-service.html

[Accessed 24 April 2017].

Marinov, M. \& Reece, D., 2015. Facilitating the Movement of Passengers by Introducing Baggage Collection Systems for travel from North Shields to Newcastle International Airport. Urban Rail Transit.

Marinov, M. \& Viegas, J., 2009. A simulation modelling methodology for evaluating flat-shunted yard operations. Simulation Modelling Practice and Theory, Volume 17, pp. 1106-1129. 
Marinov, M. V. \& Viegas, J. M., 2011. Tactical management of rail freight transportation services: evaluation of yard performance. Transportation Planning and Technology, 34(4), pp. 363-387.

Motragh, A. \& Marinov, M. V., 2012. Analysis of urban freight by rail using event based simulation. Simulation Modelling Practice and Theory, Volume 25, pp. 73-89.

Nance, R. E., 1993. A History of Discrete Event Simulation Programme Languages. Blacksburg: Department of Computer Science, Virginia Polytechnic Institue and State University.

Nash, A. \& Huerlimann, D., 2004. Railroad simulation using OpenTrack. Computers in Railways IX, Volume 74, pp. 45-54.

National Rail, 2015. National Rail Conditions of Carriage, s.l.: National Rail.

Neufville, R. d., 1994. The baggage system at Denver: prospects and lessons. Journal of Air Transport Management, 1(4), pp. 229-236.

Neufville, R. d., 1994. The baggage system at Denver: Prospects and Lessons. Journal of Air Transport Management, 1(4), pp. 229-236.

Office of Rail and Road, 2016. Estimates of station usage. [Online] Available at: http://www.orr.gov.uk/statistics/published-stats/station-usage-estimates [Accessed 10 March 2017].

OpenTrack, 2017. Railway Simulation. [Online]

Available at: http://www.opentrack.ch/opentrack/opentrack e/opentrack e.html [Accessed 01 August 2017].

Özgün, O. \& Barlas, Y., 2009. Discrete vs. Continuous Simulation: When Does It Matter? Albuquerque, s.n.

p4d, n.d. Welcome to Bag Magic. [Online]

Available at: https://www.p4d.co.uk/bagmagic/

[Accessed 13 June 2017].

Patil, S. et al., 2013. Trade-off across privacy, security and surveillance in the case of metro travel in Europe. Frankfurt, s.n.

Pouryousef, H. \& Lautala, P., 2015. Hybrid simulation approach for improving railway capacity and train schedules. Journal of Rail Transport Planning \& Management, Volume 5, pp. 211-224.

Pouryousef, H., Lautala, P. \& White, T., 2015. Railroad capacity tools and methodologies in the U.S. and Europe. Journal of Modern Transportation, 23(1), pp. 30-42.

Powell, J. P., Fraszczyk, A., Cheong, C. N. \& Yeung, H. K., 2016. Potential Benefits and Obstacles of Implementing Driverless Train Operation on the Tyne and Wear Metro: A Simulation Exercise. Urban Rail Transit, 2(3-4), pp. 114-127.

Rockwell Automation, 2017. AUTOMATED MATERIAL HANDLING SYSTEMS. [Online] Available at: http://www.rockwellautomation.com/global/capabilities/machine-equipment-builders [Accessed 01 Aug 2017].

Salter, M. B., 2008. Political science perspectives on transportation security. Journal of Transportation Security, Volume 1, pp. 29-35. 
Sedláček, M., 2014. The Use of Simulation Models for the Optimization of Transport and Logistic Company Process. The International Journal of Transport and Logistics, Volume 14, pp. 1-7.

Shalliker, J. \& Rickets, C., 2006. An Introduction to SIMUL 8. 13 ed. s.l.:School of Mathematics and Statistics, University of Plymouth.

Sipila, H., 2014. EVALUATION OF SINGLE TRACK TIMETABLES USING SIMULATION. Colorado Springs, s.n.

Tarau, A. N., Schutter, B. D. \& Hellendoorn, H., 2010. Model-Based Control for Route Choice in Automated Baggage Handling Systems. IEEE Transactions on Systems, Man, and Cybernetics, Part C, 40(3), pp. 341-351.

Tarau, A., Schutter, B. D. \& Hellendoorn, H., 2008. Travel time control of destination coded vehicles in baggage handling systems. San Antonio, s.n.

Transport Focus, 2016. National Rail Passenger Survey Spring 2016 Main Report, s.I.: Transport Focus.

Vayenas, N., Yuriy, G. \& Vayenas, N., 2005. Using Simul8 to model underground hard rock mining operations. Canadian Mining and Metallurgical Bulletin, Volume 1090, p. 75.

Vickers, K. \& Chinn, R., 1998. Passenger terminal baggage handling systems. IEE Colloquium on Systems Engineering of Aerospace Projects, Volume 6, pp. 1-7.

Vidalakis, C., Tookey, J. E. \& Sommerville, J., 1994. The logistics of construction supply chains: the builders' merchant perspective. Engineering, Construction and Architectural Management, 18(1), pp. 66-84.

Virgin Trains, n.d. Bag Magic has come to an end. [Online] Available at: https://www.virgintrains.co.uk/bagmagic [Accessed 13 June 2017].

Wales, J. \& Marinov, M., 2015. Analysis of delays and delay mitigation on a metropolitan rail network using event based simulation. Simulation Modelling Practice and Theory, Volume 52, pp. 5277.

Zeinaly, Y., Schutter, B. D. \& Hellendoorn, H., 2015. An Integrated Model Predictive Scheme for Baggage-Handling Systems: Routing, Line Balancing, and Empty-Cart Management. IEEE Transactions on Control Systems Technology, 23(4), pp. 1536-1545. 